\title{
The influence of frequency of exposure on the learning of a phrase structural grammar
}

ERWIN M. SEGAL AND TERRY G. HALWES ${ }^{1}$

ARLINGTON STATE COLLEGE

Letter pairs generated by an elementary grammar were presented to college student $S$ s for recall. Ss were given 14 trials to learn 18 pairs, using a free recall technique. These $S s$ did not reach learning asymptote. Another group of $S S$ was given 12 pairs for 20 trials. Most $S$ s did not learn the pairs in these trials. The intrusions in the recall protocols suggest that the $S s$ did not learn the grammar from which the pairs were generated, but they learned the position of the letters in the pairs and generated sequences accordingly. Some Ss seem to have leamed the presented pairs directly and these Ss tended to learn the pairs presented better. The authors concluded that mere exposure with intent to leam is not sufficient for the learning of grammatical structure.

Recent researchers (Smith, 1965; Braine, 1965; Segal \& Halwes, 1965) have found that when they presented a relatively large number of verbal sequences to a group of Ss, the Ss did not learn them all. More interestingly, when Ss are given a recall or recognition task following the presentation of sequences they make errors of commission. They generate many sequences which are not presented to them. Moreover, the generated sequences are related to the presented ones in certain specifiable ways. In addition to learning some of the sequences the Ss learn rules of combination by which they generate sequences. Evidence that Ss learn rules of combination is (1) the generated sequences contain the same elements as the presented sequences; and (2) the elements in the generated sequences appear in the same position as they do in the presented sequences. These rules can be formalized by simple generative grammars (cf. Chomsky \& Miller, 1963).

In the studies by Smith (1965), and Segal \& Halwes (1965) the Ss were given strings of sentences to learn which were generated by grammars which contained two major classes of strings. However, when the strings generated by the Ss were analysed it was found that they could be generated by a grammar which contained a single class of strings. The present experiments were designed to investigate whether Ss can learn contingencies such that both major sentence classes are necessary to describe the S's behavior.

\section{Method}

\section{EXPERIMENT 1}

The technique in this experiment is very much like that of Segal \& Halwes (1965). Ss were given a random sequence of letter pairs to learn. The pairs which they were given were generated by a grammar of the form
$\mathrm{S} \rightarrow \mathrm{A}+\mathrm{B}, \mathrm{S} \rightarrow \mathrm{B}+\mathrm{C}$. The letters $\mathrm{A}, \mathrm{B}$, and $\mathrm{C}$ stand for subclasses of consonants. For this particular study the $\mathrm{A}$ and $\mathrm{C}$ classes each contained 3 letters and the B class contained 4 letters. Of the 24 pairs which could be generated from this grammar 18 were presented to the 20 college students who served as Ss. The letter pairs were presented orally at a 3-sec. interpair interval. Ss were given $1.5 \mathrm{~min}$. to write the pairs they remembered after the presentation. The sequence of presentation of the pairs followed by recall was continued for 14 trials.

\section{Resulfs}

One analysis of the data concerns the intrusions made by the Ss in their attempt to recall the presented pairs. If they learned the pairs directly except for a few random intrusions each nonpresented pair would have equal opportunity of being "recalled." If the Ss recalled the pairs by inventing a grammar and generating the pairs then a greater percentage of the intrusions than would be expected by chance would be generated by that grammar. Three classes of intrusions were compared: (1) grammatical intrusions, those pairs generated by the grammar but not presented to the Ss; (2) semigrammatical intrusions, those dependent upon simple position in the pair (generated by a simple grammar containing a single sentence class); (3) nongrammatical intrusions, other pairings of the presented letters. The number of intrusions in each class was divided by the total number of letter pairs in that class for the analysis. This weighting procedure corrects for the opportunities each intrusion class has of occurring.

The analysis of the intrusion data showed that the Ss invented a grammar and generated pairs. There was a large difference between the number of intrusions in each class, $F=9.91, \mathrm{df}=2 / 38, \mathrm{p}<.001$. This was entirely due to the difference between the nongrammatical intrusions and the others, $F=19.69, \mathrm{df}=1 / 38$, $p<.001$. The difference between the two classes of grammatical intrusions was negligible, $\mathrm{F}=0.12$, $\mathrm{df}=$ $1 / 38$. The intrusions showed no trend effects, $F=0.78$, $\mathrm{df}=13 / 247$, and no significant trials by class interaction, $F=.79, \mathrm{df}=26 / 494$. Although the $\mathrm{Ss}$ had 14 trials to learn 18 pairs of letters there was no sign of limiting the number of intrusions over trials. Also, the Ss simply learned a two-class grammar and did not learn to condition one class of letters to another.

It was found that after 14 trials the learning asymptote was not reached. The Ss averaged only 13.7 pairs correctly recalled on the last trial and only two recalled all 18 pairs. The Ss averaged 4.2 intrusions on the 
last trial and 13 of the 20 Ss made at least one intrusion. The number of pairs recalled correctly and the number of intrusions were negatively correlated $(x=-.243)$ although insignificant.

\section{Method \\ EXPERIMENT 2}

Because of the lack of learning restrictions either by limiting the number of intrusions over trials or by learning the specific restrictions of class membership the same general task was tried with fewer pairs and more trials. The grammatical form used in Experiment 1 was again used. However, there were only three letters in each class. From this grammar 18 pairs could be generated; of these, 12 were presented to the $20 \mathrm{Ss}$ in the same manner as the first experiment. In this experiment the Ss were given one min. to write their responses and they had 20 trials.

\section{Resulis}

The analysis of the results for this experiment is generally similar to that of Experiment 1 . The intrusions were again divided into three classes and weighted for comparison. There was a large difference between the weighted number of intrusions of the three classes, $F=12.55, d f=2 / 38, p<.001$. The difference was again attributable to the difference between grammatical and nongrammatical intrusions, $F=25.1$, $\mathrm{df}=1 / 38, \mathrm{p}<.001$. There were no differences between the grammatical and semi-grammatical groups, $\mathrm{F}=0.002, \mathrm{df}=1 / 38$. Again, there were no trend or interaction effects. Most Ss again generated the pairs from a simple two-class grammar. However, the proportion of intrusions decreased from the previous experiments.

As a group, learning asymptote was still not reached, although little learning can be detected during the last 10 trials. On the twentieth trial the Ss averaged 9.7 correct pairs and 1.95 intrusions. Eight Ss recalled all presented pairs and nine made no intrusions. The number of pairs recalled correctly was inversely correlated with the number of intrusions $(r=-.569, p<.01)$. This result is not obviously artifactual since the number correct correlated strongly $(r=+.684)$ with the total number of responses emitted and there were large individual differences in this total.

\section{Discussion}

Individuals in verbal learning tend to make the assumption that given enough trials an individual will learn the task that he is given (Braine, 1965; Gough \& Segal, 1965); however, this assumption is not confirmed by the results of this experiment. Although given a relatively easy task to perform and many trials in which to learn it, all Ss did noteliminate errors, either of omission or commission. Although the Ss generally continued to generate pairs according to certain rules, none of them learned the contingent relation between the classes of letters. They still responded as though they were generating pairs from a simple one-stage two-class grammar. They learned the position of the letters in the sequence and generated sequences accordingly (cf. Braine, 1963).

The results suggest that in these particular studies there are individual differences in strategy with greater individual differences in Experiment 2. Some of the Ss attempt to generate sequences according to certain rules, whereas some of the Ss learn the pairs directly. The generative grammar, when used, was inefficient in that it generated more than twice the required number of pairs. Learning the pairs indirectly is more efficient in terms of the number of things to learn, especially for a group given a relatively small number of sequences. This efficiency is noted in the negative correlation between the number of intrusions and number of sequences emitted correctly. The Ss who adopted a rote learning strategy learned a greater number of the sequences and made fewer intrusions than Ss who generated pairs from the grammar.

The results of these experiments also suggest to the authors that Ss will not learn specific class contingencies from mere exposure to sequences generated according to those contingencies. In most studies using artificial grammars the contingency learned by Ss may be described primarily by position. Braine's (1963) theory of position of learning seems to be a good statement of what Ss do. However, an analysis of real language leads one to the conclusion that position learning is not sufficient to explain linguistic complexity. A conclusion reached is that other variables formally independent of the linguistic structure must covary with the structure in order for Ss to learn the contingencies implicit in the structure. Possible correlated variables are stress patterns and associated stimulus classes, among others.

\section{References}

Braine, M. D. S. On learning the grammatical order of words. Psychol. Rev., 1963, 70, 323-348.

Braine, M. D. S. The insufficiency of a finite state model for verbal reconstructive memory. Psychon. Sci., 1965, 2, 291-292.

Chomsky, N.. \& Miller, G. A. Introduction to the formal analysis of natural languages. In R. D. Luce, R. R. Bush, and E. Galanter (Eds.), Handbook of mathematical psychology. New York: Wiley, 1963, 2, 269-321.

Gough, P. B., \& Segal, E. M. Comment on "The insufficiency of of a finite, state model for verbal reconstructive memory." Psychon. Sci., 1965, 3, 155-156.

Segal, E. M., \& Halwes, T. G. Learning of letter pairs as a prototype of first language learning. Psychon. Sci., 1965, 3, 451-452.

Smith, K. H. Mediation and position learning in the recall of structured letter pairs. Psychon. Sci, 1965, 2, 293-294.

\section{Note}

1. Now at University of Minnesota. 